\title{
Schooling Teachers, Schooling Ourselves: Insights and Reflections from Teaching K-12 Teachers How to Use Hip-hop to Educate Students
}

\author{
Decoteau J. Irby, Ph. D. \\ University of Wisconsin - Milwaukee \\ U. S. A. \\ H. Bernard Hall, Ph. D. \\ West Chester University \\ U. S. A. \\ Marc L. Hill, Ph. D. \\ Teachers College, Columbia University \\ U. S. A.
}

Hip-hop-based education (HHBE) research analyzes how hip-hop culture is used to produce favorable educational outcomes. Despite its richness, the work reveals little about how to prepare practicing K-12 teachers to use HHBE toward the critical ends reflected in extant HHBE literature. In this article, we challenge many tacit assumptions of HHBE research by examining the curricular and pedagogical wants and needs of in-service teachers who are interested in HHBE but who are not familiar with hip-hop's unique history and culture. Through a collaborative self-study with a teacher-educator, we, as Black male hip-hop insiders, reflect on the promises and pitfalls of preparing predominantly White teachers to incorporate hip-hop into their teaching and learning repertoire.

$$
\begin{gathered}
\text { Introduction } \\
\text { Theoretical Framework } \\
\text { Statement of the Problem and Research Questions } \\
\text { Research Methods } \\
\text { Data Collection and Analysis } \\
\text { Lessons Learned from Schooling Teachers } \\
\text { Less Legitimacy, More Cultural Content } \\
\text { The Importance of HHBE Content and Pedagogy } \\
\text { Constraints of HHBE } \\
\text { Conclusion: Schooling Ourselves } \\
\text { References }
\end{gathered}
$$

"I think it would have been helpful if you had an idea of who your participants were and how much info they had on hip-hop."

(Hip-hop-based education workshop participant) 
An increasing number of $\mathrm{K}-12$ teachers are seeking professional development with hopes of deepening their understanding of how hip-hop culture can be used for educational purposes. Hip-hop's connection to education is not new. It has long been considered a driving force in education for urban youth (Powell, 1991). The first arena where hip-hop was recognized as an educational force was the streets (e.g., Powell, 1991; Sullivan, 2003). As early as 1991, educators began tapping into the music and culture as a means of exploring "the values and attitudes of young people" (Powell, 1991, p. 257) as well as of teaching language arts (Jeremiah, 1992). More recently, a burgeoning body of research known as "hip-hop-based education" (HHBE) (Hill, 2009; Petchauer, 2009) has demonstrated the ways that hip-hop culture can be used to produce favorable educational environments and student outcomes. Specifically, HHBE research reflects how hip-hop cultural texts (most often in the form of printed rap lyrics) can improve student motivation, increase achievement, nurture critical literacies, and strengthen classroom community (Camangian, 2008; Emdin, 2010; Hill, 2009; Morrell \& Duncan-Andrade, 2002).

Many of the research studies in the field are written by teacherresearchers who possess relatively deep understandings of hip-hop culture and of critical and culturally relevant theories of teaching and learning. Although critical and culturally relevant pedagogies are well known among the general teaching population (although not necessarily practiced), how hip-hop can serve as a conduit to develop critical literacies may not be as clear for educators who lack a knowledge base in hip-hop culture. While extant studies are indispensable, the teacher-researcher studies do not account for the demographics of the teaching workforce or the "questions of identity" (Hall, 1996) that inform teacher effectiveness. With these shortcomings in mind, we raise new theoretical questions, assume new methodological approaches, and locate new units of analysis that speak to an international audience of multicultural education scholars and practitioners seeking to explore and understand the possibilities and pitfalls of HHBE.

This article shares findings from a self-study of a hip-hop insider and educator named Decoteau. We explore his evolving assumptions and educational practices in a professional development series designed to teach $\mathrm{K}$ 12 teachers how to incorporate hip-hop into their teaching and learning practices. Upon invitation, Bernard and Marc (Authors 2 and 3) participated as coresearchers to analyze the experiences and philosophical adjustments that challenged Decoteau to re-think his assumptions about who could and should use hip-hop for educational purposes. The three authors are Black male "hip-hop generation" scholars (Kitwana, 2002). By owning these identities, we recognize that our cultural lenses and worldviews from inside hip-hop and the academy distinguish us from the many White, female hip-hop cultural outsiders interested in HHBE (Irby \& Hall, 2011). We acknowledge that HHBE in the typical K-12 classroom probably looks very different than it does in the portrayals reflected in the literature. 
In this study, we use Decoteau's local experiences to juxtapose the tacit assumptions of HHBE research against the curricular and pedagogical wants and needs of in-service teachers seeking to incorporate hip-hop in their teaching and learning. Through critical considerations of the wants and needs of the teachers, participants schooled us in three ways. First, teachers wanted workshop content to be less focused on the legitimacy of HHBE and more practically oriented for classroom application. Second, modeling the use of technology, hip-hop media texts, and hip-hop aesthetics increased teacher enthusiasm and confidence to attempt HHBE in their classrooms. Finally, teacher interest in HHBE was dampened by the real and perceived constraints of engaging hip-hop in traditional school contexts. Such insights are critical for developing more pragmatic, relevant, and responsive hip-hop-based educational training.

\section{Theoretical Framework}

We use hip-hop pedagogy (Emdin, 2008; Duncan-Andrade \& Morrell, 2005; Morrell \& Duncan-Andrade, 2002; Rice, 2003; Stovall, 2006) and critical multicultural teacher education for White teacher candidates (Banks, 1995; Lensmire \& Snaza, 2010; Lowenstein, 2009; Milner, 2005) as theoretical guides for this study. HHBE researchers have primarily used critical (Emdin, 2008; Morrell \& Duncan-Andrade, 2002; Duncan-Andrade \& Morrell, 2005; Stovall, 2006) and culturally relevant (Abowitz, 1997; Alexander-Smith, 2004; Hill, 2009) frameworks for orienting their respective pedagogies and outcomes. LadsonBillings (1992) posits, "While critical pedagogy seeks to help the individual critique and change the social environment, culturally relevant pedagogy urges collective action grounded in cultural understandings, experiences, and ways of knowing the world" (pp. 382-383). Hip-hop pedagogy fuses the "understandings, experiences, and ways of knowing the world" relevant to hip-hop culture with critical theories of teaching and learning aimed at "empowering students and transforming the larger social order in the interests of justice and equality" (McLaren, 2007, p. xvii).

This study is timely, given current discourses in the literature on multicultural teacher education/development and questions of how, if at all, to prepare a largely White middle-class teacher (and teacher-educator) workforce to become multicultural learners capable of understanding and appreciating diversity (Lowenstein, 2009). Banks (1995) argues that multicultural education is designed "to help all students, including White mainstream students, to develop the knowledge, skills, and attitudes they will need to survive and function effectively in a future U.S. society in which one out of every three people will be a person of color" (p. 23). In response to Lowenstein's (2009) article on the representation of racial identities of White prospective teachers in educational research, Lensmire and Snaza (2010) offer three considerations for researchers and teacher educators charged with narrowing the "demographic divide" (Banks, 1995; Dilworth, 1992; Gay \& Howard, 2000) between teachers and students: (a) one must assume (or at least entertain the notion of) an ambivalent White self, 
(b) White ambivalence both endangers and enables a multicultural and antiracist teacher education, and (c) teacher education is, among other things, a site of hegemonic struggle among White people (p. 420).

Heeding the warnings included in Lensmire and Snaza's (2010) first two prescriptions and recognizing the history of Whites' authentic and counterfeit interests in the production and consumption of Black culture, we extend the arguments and conceptions of Lowenstein and Banks to frame the in-service teachers in our study as students of HHBE. Insights garnered here are particularly pertinent to Lensmire and Snaza's latter point, as we as "hip-hop pedagogues" consider both the pedagogical challenges and the cultural-political implications of teachers' engagement with hip-hop in various, possibly homogeneous, schooling contexts underrepresented in HHBE scholarship.

\section{Statement of the Problem and Research Questions}

Within current HHBE research, most studies focus on individual teacher accounts of local curricular interventions (Hill, 2009; Petchauer, 2009). To the best of our knowledge, no studies examine what hip-hop-based teacher education looks like. In other words, besides reading texts, what do practicing teachers need in order to be prepared to use HHBE toward critical educational ends? Current research does not address the challenges teacher-educators may face in preparing prospective teachers to use hip-hop in their classrooms. Nor does it attend to the many issues (pedagogical and/or institutional) that practicing researcher-teachers contend with when developing and implementing hip-hopbased curricular interventions. Such areas of inquiry are crucial, given the growth in numbers of research publications, curricula, professional development opportunities, and conferences that encourage more extensive use of culturally relevant teaching generally, and of $\mathrm{HHBE}$, more specifically. The following research questions guided our inquiry:

1. What are the assumptions that we (i.e., hip-hop insiders, hip-hop pedagogues) make about who uses or desires to use hip-hop-based education and toward what ends?

2. What challenges might teacher-educators face when attempting to balance the learning needs of teachers unfamiliar with hip-hop culture while honoring the critical and culturally relevant tenets of hip-hop pedagogy?

\section{Research Methods}

\section{Study Context and Participants}

Data for this study were drawn from four teacher education workshops that Decoteau developed and led from 2006 to 2008. The workshops lasted approximately four hours each, were offered as part of a local museum's ongoing multicultural professional development programming for educators in the 
Philadelphia region of the United States. Each workshop was attended by 27, 13, 18 , and 25 different participants, respectively. Attending teachers typically worked in one of two school settings: a suburban school with a majority White student population or a non-traditional (private or charter) urban school that served a majority of students of color. An equal number of urban and suburban schools were represented. A majority were certified in their respective subject areas and resided in suburban residential areas (Irby \& Hall, 2011). Playing on the hip-hop slang term of "schooling" (i.e., teaching) someone, the initial objective of the "Schooling Ourselves" workshop was to prepare educators to effectively make use of a newly developed hip-hop-based curriculum and learning guide (Irby, 2006).

\section{Self-study Research}

Decoteau initiated a self-study to challenge his own assumptions and practices after conversing with colleagues about the dilemmas of teaching cultural outsiders how to use hip-hop in their classrooms. Realizing the limits of his own reflections, Decoteau invited Bernard and Marc to collaborate with him in a study of himself in relation to others (Hamilton, Smith, \& Worthington, 2008). The formal process was conducted over a period of two years beginning in November 2006 and ending after a workshop held in March 2008. To investigate Decoteau's evolving practice and our collective perceptions about who could effectively make use of HHBE to achieve critical ends, we analyzed workshop content, delivery, and participant feedback, and engaged in reflective dialoguing sessions to offer Decoteau critical feedback on content and delivery of the workshops.

LaBoskey (2004) identifies five key elements of any self-study: they are (a) self-initiated and focused, (b) aimed at improving teaching practice, (c) interactive in nature, (d) reliant of multiple methods of data collection and analysis, and (e) dependent on triangulation of data to establish validity. Additionally, self-studies often rely on dialogue, recognizing it as the basis from which to assert the authority of claims made and as a way to expose ontological understandings of practical actions (Pinnegar \& Hamilton, 2009). Addressing the underlying assumptions ideally yields changes to the practices employed and to the technical aspects of teaching. Strong self-studies involve co-researchers who help the subject examine his or her practices. Loughran (2006) argues that selfstudies are valuable because a collaborative approach to the study of the self allows new understandings to emerge. This collaborative process of clarifying problems occurs through noticing (Mason, 2002) and framing (Loughran, 2006) problems. When multiple collaborators are engaged in a self-study, more is likely to be noticed about a problem, which is likely to allow issues to be framed (i.e., explained and explored) in multiple ways. Further, situations are clarified as questions are pursued by people other than the subject of study. Problems are viewed in new ways that the subject of the study may be unaware of. 
We chose to conduct a collaborative self-study because we determined that the root problems associated with HHBE are ontological and epistemological in nature, not merely technical. Decoteau and his colleagues primarily sought to question deeply held beliefs and assumptions about what hip-hop pedagogy is, who it is for (i.e., which K-12 teachers and students), and what happens when it is taken up by cultural outsiders. Findings of self-studies are considered important to informing a professional knowledge base, as well as general understandings that contribute to understanding societal problems (Hamilton, 2004).

\section{Data Collection and Analysis}

\section{Step 1: Analysis of Workshop Content, Delivery, and Participant Feedback}

After each workshop, the researchers collaborated to analyze open-ended survey responses and consider the strengths and weakness of the content and pedagogy with a focus on helping Decoteau strengthen the workshop. We used the rubric to organize and analyze various aspects of the workshop such as agendas and PowerPoint presentations (to examine sequencing, objectives, etc.); handouts and music and video clips; teaching strategies and activities; pacing; and other curricular materials as well as practices integrated into the workshops. Thus, we developed the following categories:

- Content Knowledge: use of teacher manual, books, and curriculum guides

- Initiative/Collaboration: asks questions, seeks to expand opportunities

- Instructional Planning: objectives, sequencing, assessment

- Instructional Strategies: question-asking, technology integration, grouping arrangements

- Participant Motivation: expectations, interest, choice, level of engagement

- Response to Diversity: awareness of individual differences, inclusion of multicultural materials

- Practitioner Reflection: self-evaluates, connects theory to practice, sets goals

\section{Step 2: Reflective Dialoguing Sessions}

After reviewing materials to complete rubrics, we engaged in four 3-hour audio-recorded reflective dialogue sessions. Using the rubrics, we conversed with Decoteau about participant feedback from open-ended survey questions with a focus on noticing what aspects of the workshop required additional attention, what seemed to work well, and what issues remained unaddressed. Since we wanted to understand Decoteau's assumptions, we probed him for why he made certain decisions at certain times. We spent substantial time 
considering assumptions, teacher identities, and ourselves in light of the HHBE literature. These discussions illuminated the deeply held assumptions ingrained into HHBE research assumptions that Decoteau held, but actively challenged, in each subsequent workshop.

\section{Step 3: Modifying Workshop Protocol and Content}

Based on ongoing analysis and dialogue of steps 1 and 2, Decoteau iteratively reorganized workshop protocol, instructional materials, and instructional methods (e.g., lyrics, PowerPoint presentations, media clips, and learning activities) to improve his practice by aligning the workshop to the needs of the participants. The reorganization of the workshop was incremental. Over time, the data collection and organization activities yielded four sets of rubrics, audio-recorded conversations, detailed notes, and memos that reflected workshop modifications to better suit the interests and needs of the workshop participants. The dialogue sessions illuminated the rationales for why the changes were made and how they challenged us to imagine new ways that hiphop might operate in educational spaces. By juxtaposing the workshop materials (researcher reflections and changes in course content and methods) vis-à-vis teacher evaluations (open-ended survey response), we determined the usefulness of content, pedagogical, and technological changes. After the final workshop, all three researchers collaborated to determine major themes that emerged from the self-study.

\section{Lessons Learned from Schooling Teachers}

\section{Understanding the Self}

Decoteau initially designed the workshop with two goals in mind. The first was to help teachers understand how to teach cultural literacy, critical literacy, and media literacy through hip-hop. This goal focused on preparing teachers to address race, gender, class, oppression, cultural appropriation, capitalism, sexism, and other critical societal issues in the classroom. The second, more implicit goal sought to assuage teachers' preconceptions about the academic rigor and legitimacy of HHBE. This objective of convincing teachers of the merit and legitimacy of HHBE was not what teachers wanted or needed. Few questioned the importance of or need for critical and culturally relevant education. In fact, about a third of teachers reported using hip-hop in their teaching prior to the workshop. Their central concern was that they did not have sufficient understandings of hip-hop's historical and social development such that they could effectively engage it in the classroom setting to achieve critical ends.

At the onset, Decoteau approached workshop participants, the vast majority of whom were White females, as a monolithic group of culturally deficient learners. He did not presume the teachers would be willing to reflect on their racial identities and challenge their racial privileges and biases. He also believed that the teachers did not possess legitimate knowledge about hip-hop. 
He also presumed that workshop participants taught in secondary urban schools with "at-risk" student populations. One of the major quandaries to emerge from reflective dialogue sessions was Where did these assumptions come from? We conceded Lowenstein's (2009) point that Decoteau was in fact viewing teachers through the same deficit lens we teach teachers not to use. However, unlike the majority of teacher educators, he did so as a Black male of the "hip-hop generation" with professional and equally important personal experiences living, learning, and teaching in urban schools and communities.

As scholar-activists teaching in and researching for predominantly White institutions of higher learning, we confront the "dysconscious racism" (King, 1991) and "rhetoric of American equality" (Darling-Hammond, 2000) that relegate non-Eurocentric epistemologies and critical approaches to multicultural education to the periphery of discourses on educational policy and practice. Workshop participants challenged Decoteau, and by extension each of us, to reconsider our generalizations of White teachers as ostensibly racist. In particular, Decoteau learned not to mistake teachers' limited hip-hop knowledge bases as disdain for hip-hop and/or Black youth. Instead, he sought to use their prior knowledge, however limited and/or "illegitimate," as a point of departure to scaffold teachers to the history, aesthetics, and content required to use HHBE and, more importantly, maximize the academic and socio-cultural outcomes of their students.

Decoteau also assumed that teachers worked in secondary urban schools with "at-risk" student populations. This assumption impacted his pedagogical approach to the workshop in two ways. First, he decided to make minimal use of technology, particularly audio-visual and Internet activities, as a means of representing hip-hop culture. He internalized a belief, based on the research literature and his own experiences, that urban schools lacked access to such technologies. Consequently, he downplayed the use of technology. His assumptions about participants' workplaces proved to be shortsighted. Typical attendees were "suburban certified primary school teachers with more than 10 years of teaching experience who were likely to work in either primarily White suburban or primarily non-traditional (charter or private) urban schools" (Irby \& Hall, 2011).

The second impact is related to the first. Decoteau foresaw (though in retrospect perhaps inaccurately) the challenges of preparing White teachers to negotiate the cultural-politics of HHBE with Black students in under-resourced secondary schools. Yet, he had not fully considered the cultural-political and subsequently pedagogical implications of teaching White teachers how to use HHBE with predominantly White student populations or in suburban, elementary, and non-traditional schooling contexts. He understood school settings for "at-risk" to be characterized in one of two ways. They were either highly regulative settings where teachers have little to no curricular and instructional autonomy or loosely structured environments where pedagogically "anything goes as long as they're not killing each other." 
Decoteau's assumptions were not his alone but, as we came to realize, were reflections of collective assumptions of hip-hop insiders. They also reflected the methodological and theoretical shortcomings of HHBE scholarship, namely the dearth of research that problematizes critical issues of power and pedagogy as they pertain to HHBE's appropriateness, let alone effectiveness, in various instructional contexts. Decoteau discovered that he had miscalculated both the needs of the participants, as well as the nature of their school contexts. The following sections detail how the self-study process helped Decoteau refine the workshop and redefine the teachers in light of his critical exploration and understandings of the self.

\section{Less Legitimacy, More Cultural Content}

In the first workshop, Decoteau used a PowerPoint presentation and lecture based on the content of the "Do the Knowledge" learning and activity guide. The presentation contained pictures and hip-hop music. No videos supplemented the discussion of hip-hop cultural art forms. Much of the lecture, complete with a brief review of literature, aimed to provide academic justifications for using hip-hop as an educational tool. Respondents reported that the presentation was overly academic. For example, one survey respondent, a fourth grade teacher, expressed "[although] the presenter was very knowledgeable in hip-hop culture, I did not find this workshop to be useful. I learned some things from him, but I did not gain an understanding of how to correctly incorporate it into the classroom." The comment characterized the sentiment of several workshop participants, who made it clear that they were not looking for theoretically-driven lectures that stressed the intellectual legitimacy of HHBE and other forms of critical and culturally relevant pedagogy. Rather, they were interested in vocationally practical tools that could be directly employed within their classrooms.

In response to the teacher feedback, Decoteau incorporated abridged lessons and activities from the curriculum guide into the workshop. Instead of an introductory lecture, the revised sessions used a lesson called "What is HipHop?" Participants began by responding to a seemingly simple writing prompt: What is culture? The second writing prompt asked another seemingly simple question: What is hip-hop? After participants wrote responses, they discussed their answers in small groups. Following group discussion, the entire class completed a "Culture Rubric" to identify several common features of culture, including values, language, groups and institutions, ways of life, traditions, and cultural products (art, writings, etc.). The rubric examined hip-hop alongside other cultures the participants identified with. The objective was not to arrive at a consensus about the legitimacy of hip-hop, but rather to consider more deeply the concept of culture, its components, and to offer a starting point for the remainder of the workshop. It also modeled how to integrate hip-hop into their curriculum, since the lesson was not about hip-hop per se, but about the bigger issue of culture. By addressing teacher participant feedback, Decoteau identified the deficit thinking he had utilized to approach his participants earlier. His new 
approach framed teachers as students of $H H B E$, and by extension he shifted his pedagogy to meet the needs of the students by meeting them where they were.

In addition to asking for concrete classroom tools, participants also expressed an interest in learning more about the historical and social context of hip-hop culture and rap music. Technology enhanced these understandings. In early workshops, Decoteau assumed teachers would have minimal access to technology in their schools. He used technology minimally. However, the attendees not only expected instruction to integrate technology, but greatly desired technology-driven approaches to facilitate their own learning. As Decoteau adjusted to these requests, teachers shared their appreciation:

Excellent video presentation and info on additional web resources available on the subject. (Pre-K Teacher)

The videos and songs truly supplemented the lecture. (Middle School Teacher)

The visual and hands on presentation showed us how to connect with our student's worlds - terrific. (High School Teacher)

The texts that evoked these responses consisted primarily of video clips from "old school" hip-hop movies and a range of old and new rap songs. Clips from the movies Wild Style (1983) and Style Wars (1983) gave life to lectures by providing teachers with windows into the historical and social contexts and conditions that spawned hip-hop aesthetics and cultural practices. Style Wars illustrates the camaraderie of the early graffiti scene, young people's enthusiasm for their craft, and their critique of the established norms concerning what constitutes lawfulness, art, and decency. Teachers also discussed the film subjects' ambitions to move local "jams" beyond the South Bronx into Manhattan (Wild Style) or to go "all city" by having their graffiti art represented throughout the entire New York metropolitan area (Style Wars). How might these themes be used to probe youth's ambitions to move beyond their immediate circumstances for both for material and psycho-social reasons? Decoteau drew out discussions about the parallels drawn between the films' characters and those of students in urban schools.

More practically, the use of media enhanced the teaching of what is largely a performance-oriented and participatory set of cultural practices. Showing "breakdancing" was considerably more effective than attempting to describe it. So, too, was helping the teachers identify "break beats" while watching hip-hop pioneer and innovator Grandmaster Flash engage in juggling records, as portrayed in Wild Style. The breaks of the records the DJ spins connect directly to the performances by breakdancers. These connections become apparent when viewed in practice. Through watching video clips, participants witness how one element discursively informs others. When cultural outsiders are exposed visually to a cultural event such as "DJs playing breaks" to entice "b-boys and b-girls to dance" while "MCs rock the mic," they are able to make meaningful connections. As the course developed, the focus on illustrating the continuity of cultural production and knowledge production that provides the 
crux of hip-hop texts became more prominent. Decoteau engaged a similar integration of elements as his teaching evolved, as will be discussed in the next section.

While technology is generally viewed as a valuable resource for teaching and learning, it is particularly integral to HHBE because hip-hop culture relies heavily on oral, visual, performative, and kinesthetic ways of being, doing, and knowing. Music videos helped teachers to grasp the historic context of the lecture, visualize the living conditions from which hip-hop spawned, and appreciate various cultural artifacts. Through our dialogue and analysis, we realized the use of technology in HHBE is paramount, especially for preparing cultural outsiders to understand hip-hop.

\section{The Importance of HHBE Content and Pedagogy}

Using technology and appropriate texts to explore the history and aesthetics of hip-hop culture with increasing depth spawned heightened interest from participants in how to use hip-hop texts to teach rather than simply seeking to understand the content of hip-hop texts:

I found that I have been introduced to hip-hop and now understand some important aspects of hip-hop. I do use music very often in my classes for students to understand their information. I would have liked to be able to go through a song to understand how you worked directly with students. (anonymous respondent)

Facilitating the process of teaching "how" required a re-evaluation of the workshop's pedagogical aims, sequencing, and objectives. We collectively worked to design a more fluid, fast-paced workshop that modeled more accurately what HHBE could look like in the classroom. By the final workshop, participants engaged through call-and-response activities, small group breakouts, and role playing that guided them through content and pedagogy. The workshop afforded participants the opportunity to experience the aesthetic dimensions of hip-hop pedagogy in a hip-hop friendly space, complete with music, participatory learning, hip-hop-based and inspired idioms (i.e., asking participants to form discussion "crews" instead of groups) and engagement with hip-hop texts. In essence, the style in which the workshop was delivered, as well as the instructor himself, became texts for participants to examine and learn from. Simultaneously, the participants were required to draw from their own experiences and cultural references to learn about hip-hop music and culture.

The workshops became more focused on helping teachers articulate what they already knew so that they could build from and on pre-existing knowledge to interrogate their privileges. For example, discussion crews were asked to develop working definitions of hip-hop culture and to present them back to the class. By drawing from all of the expertise in the classroom, what was previously a lectured explanation of "What is hip-hop culture?" was reconfigured into an active learning exercise, complete with dissent, critique, and opposing views, that 
drew from the expertise of participants. To deepen and further explore the existing knowledge of the participants, technology and hip-hop texts supplemented, supported, and challenged, rather than simply deposited hip-hop cultural practices and expressions.

Modified workshop materials and texts became a starting place for engaging participants' knowledge, however limited. One example of drawing from more culturally relevant texts, given our new considerations of workshop audiences, was to primarily use old school hip-hop texts before introducing contemporary artists and music. Decoteau incorporated pop singer Blondie's song "Rapture" from the album Autoamerican (Harry \& Stein, 1980, track 9) to highlight the transition from rap as a localized youth phenomenon to a mainstream commodity consumed by a popular public. In the final verse of the song, Blondie pays homage to the South Bronx rap scene and its pioneers by rapping, "Fab Five Freddy told me everybody's fly / DJs spinning is in my mind / Flash is fast, Flash is cool ... and you don't stop." The verse, the first rap to appear on a pop album, connects directly to film clips in the movie Wild Style (Ahearn, 1983).

Earlier in the workshop, participants watched the film Wild Style to learn about DJ-ing by watching clips of Grandmaster Flash. Using texts in this manner helped participants understand how the music and other commodities of hip-hop connect directly to local conditions, happenings, and people. Many participants, familiar with Blondie and the song "Rapture," found a new appreciation for her numerous references to the rap scene, its practices, and pioneers, as depicted in Wild Style. Many took away new meaning from a text for which they were already somewhat familiar. Blondie also presented an opportunity to engage discussion on unspoken concerns (of hip-hop and cultural outsiders) about whether teaching with hip-hop is performing "blackness." By showing such connections between texts and lived realities, participants were more inclined to understand the relation of hip-hop texts to people's lives.

To explore hip-hop's inclination towards social commentary and critique, Decoteau employed a similar strategy to that used with the Blondie song to bridge teachers' understandings of unfamiliar texts by first exploring texts that might be more familiar. In the second example, teachers read and listened to Grandmaster Flash and the Furious Five's song "The Message" (Fletcher \& Glover, 1982, track 7). "The Message" is considered the first rap song that moves decidedly away from party-themed dance music towards full-fledged social commentary. It is also the first rap song acknowledged by the National Recording Registry as culturally, historically, and aesthetically important for the ways it informs or reflects life in the United States-a fact that is highlighted during the workshop. After listening to the song, teachers were asked to identify themes and discuss them in the context of today's society.

This exercise allowed participants to understand the importance of social critique and "droppin' knowledge" as a central element of hip-hop culture, an aspect that most viewed favorably. Many participants, as expected, were familiar with the song "The Message" and its popular lyrics, especially the chorus "don't 
push me 'cause I'm close to the edge / I'm tryin' not to lose my head." In analyzing and discussing the content of the song, the instruction relied on probing questions instead of providing explanations. Rather quickly, participants recognized oppression, poverty, hope, and decision-making as appropriate and timely conversation starters with their students and underscored the universal applicability and appeal of "The Message." Through examining how and why this song appealed to them, the participants were able to imagine how the aesthetics and content of contemporary rap music might appeal to and promote learning and engagement amongst their students.

In approaching the use of texts in the described manners, Decoteau's pedagogical strategies reflected a commitment to using the participants' knowledge as a starting place for exploring the issue of how to use HHBE, a strategy that is central to hip-hop-based teacher education. Moreover, these learning activities provided a springboard to examining contemporary rap music, music that many viewed with guarded suspicion (see "Constraints of HBEE"). Songs and lyrics of contemporary rap artists Common and Lupe Fiasco, such as "The Corner" (Common, 2007, single) and "Hurt Me Soul" (Fiasco, 2006, track 11) respectively, were juxtaposed with Grandmaster Flash and the Furious Five's "The Message" (Fletcher \& Glover, 1982, track 7). By this point in the workshop, teachers were prepared to move iteratively between content and pedagogy to explore curricular issues. Teachers were finally ready to engage critical issues in HHBE. Consequently, lessons from the "Hip-Hop Learning Guide" (Irby, 2006) became increasingly useful.

Whereas early workshops moved immediately into sample lessons from the curriculum guide to "teach" teachers how to incorporate hip-hop into their teaching and learning practices, by the final workshop, little time remained to explore the actual lessons in the guide. We realized that before the curriculum lessons could be of use, teachers needed a basic foundation of hip-hop knowledge. Consequently, learning activities were practiced very quickly, leaving little time to "do" lessons, especially considering the importance of incorporating questions and answers and allowing ample time to complete course evaluations and feedback. Time constraints undoubtedly led one respondent, a local college professor, to suggest that "perhaps a morning and afternoon solely for hip-hop, morning - history and background; afternoon - several teaching activities" would be more fitting to prepare teachers to effectively use HHBE. In sum, the workshop evolved into an explanation of culture and exploration of how youth culture might provide possibilities for teaching and learning.

\section{Constraints of HHBE}

When the workshops began providing more concrete learning opportunities and incorporating technology, most of the participants expressed a heightened level of engagement and motivation with regard to using HHBE in their classrooms. These feelings were strongly countervailed, however, by the constraints of their respective institutional contexts. In particular, respondents expressed concern about the viability of HHBE due to the content of hip-hop 
texts, as well as the curricular demands of their particular institutions. Although participants shared that the effective use of technology was one of the more engaging and effective ways for them to grasp the information presented at the workshops, this too posed challenges. Whereas basic computer and Internet technologies are absolutely essential for both the teacher-educator and K-12 practitioner interested in teaching and learning HHBE, respondents identified Internet access and content filters as one of many critical issues in need of attention.

As we effectively addressed issues pertaining to content and pedagogy, the most prominent concerns of teachers shifted to critical issues of language, violence, misogyny, age-appropriateness, institutional constraints, race, class, and gender. Many teachers expressed apprehensions that hip-hop texts, while useful, contained lyrics that were too offensive, inflammatory, or otherwise inappropriate for classroom usage. This sentiment was particularly common among teachers from elementary and religious-based schools, who regularly expressed concern about how they could integrate HHBE in their lessons, as well as the professional consequences of doing so. "Diane," an elementary school teacher in a Catholic school, informed Decoteau that "It would be more helpful to me if more info could be provided on lessons to use with younger students. More info on how to address the violent perspective of hip-hop with younger students [would have been useful too]." A teacher from a Christian primary school further complicates the issue of age appropriateness by injecting institutional pressures into the conversation: "I greatly appreciate how this would help students think critically and evaluate their values. It would be difficult in my $4^{\text {th }}$ grade class and the school culture that I am a part of." Although we discussed these critical issues, it was usually in the final minutes of the workshop during Q\&A or after the workshop officially ended. We know little about how teachers manage these sensitive matters and believe this is an area that warrants further inquiry.

Participants also expressed concern about their ability to fit the workshop ideas within the constraints of their curriculum. Many respondents echoed the statement of a suburban middle school teacher who indicated that the "presentation was well done and I'm leaving here with a lot of ideas. However, I wonder how l'll be able to incorporate them within the constraints of my district's curriculum." Such anxieties fall in direct contrast with the feedback provided by a teacher from an Afrikan-centered charter K-8 school who writes, "The mission of our charter school has made this particular area of study very important in the success and achievement of our students. Awesome!" Such feedback suggests that teachers' willingness and ability to employ HHBE in their classrooms may be influenced by the larger missions of the schools and the competing notions of teaching and learning operating within them. These issues underscore the significance of institutional context in affording or disallowing opportunities for $\mathrm{HHBE}$ to be integrated into formal teaching practices. 


\section{Conclusion: Schooling Ourselves}

Being knowledgeable about who teachers are and the knowledge bases they possess helps to determine the appropriate balance of history, aesthetics, content, and pedagogy that should be incorporated into teacher education. To understand the content within hip-hop texts, teachers must first understand the aesthetics of hip-hop culture, rap music, and its relation to the "way of life" of urban America. Basic understandings of hip-hop's historical and cultural origins are prerequisites for teachers to imagine the "radical possibilities" of hip-hop in the classroom. Thus, with regards to HHBE and multicultural education generally, it seems the question of "Whom are we schooling?" must be asked and answered by teacher-educators prior to "How are we schooling?" These insights force hip-hop pedagogues to critically reflect upon what Ellsworth (1997) refers to as mode of address, or a consideration of intended audience of curricular and pedagogical interventions. Knowing who participants are culturally, as well as the ideologies shaping their beliefs about teaching, may help teacher-educators determine the appropriate balance of history, aesthetics, and content given a particular teacher's and/or context's wants and needs. We are experiencing a generational shift in the U.S. teaching force. Because of this shift, along with the increased presence of hip-hop culture within American culture, many educators no longer view hip-hop culture with the same air of skepticism common in the early stages of HHBE. Our findings indicate that many educators recognize the intellectual merits of hip-hop culture.

The fact that more teachers wish to use classroom spaces to engage in conversations about the legitimacy of hip-hop and to use hip-hop as a tool for teaching and learning provides new directions for research. HHBE scholars should begin developing projects that identify and address the specific epistemological, ontological, and pedagogical issues associated with hip-hop within educational and broader public spheres. Future studies might include comparative research to understand HHBE across global cultural geographies (Porfilio \& Viola, 2012) or experimentally oriented research designs that determine effects of HHBE on specific academic outcomes. The proliferation of HHBE makes these sorts of investigations possible. Moving HHBE research in such directions will undoubtedly move the field into the philosophical terrain of who should or should not school in the ways of hip-hop, and why or why not. This central question of legitimacy as it relates to identity, rather than hip-hop itself, will be critical to the further development of the field. An inherent challenge is for teacher-educators to engage in processes that interrogate the assumptions that shape hip-hop pedagogy.

As illustrated in this article, there are likely deeply held assumptions that all teachers are not capable multicultural learners and teachers. Further, there are unanswered questions within hip-hop concerning just how uniform and progressive (e.g., radical, emancipatory, capitalist) individual hip-hop cultural identities and pedagogies are. Certainly there are challenges associated with "outsiders" engaging in any cultural project that is not their own. However, the unwillingness of the field, and in particular that of teacher-educators who identify 
with hip-hop culture, to consider such a fundamental shift stifles the potential of HHBE to challenge color-blind ideologies and philosophies (Johnson, 2002; Milner, 2003, 2005; Milner \& Smithey, 2003) and interrupt the White privilege that circulates throughout White-dominated educational contexts at large. To centrally acknowledge HHBE's widespread use by cultural outsiders is to also recognize and consider the broader possibilities and limitations of this educational form.

\section{References}

Abowitz, K. (1997). Horatio Alger and hip-hop. The Review of Education/ Pedagogy/Cultural Studies, 19(4), 409-425.

Ahearn, C. (Producer \& Director). (1983). Wild style [Motion picture]. United States: First Run Features.

Alexander-Smith, A. (2004). Feeling the rhythm of the critically conscious mind. English Journal, 93(3), 58-63.

Banks, J. A. (1995). Multicultural education: Historical development, dimensions, and practice. In J. A. Banks \& C. A. McGee Banks (Eds.). Handbook of research on multicultural education (pp. 1-24). New York, NY: MacMillan.

Camangian, P. (2008). Untempered tongues: Teaching performance poetry for social justice. English Teaching: Practice and Critique, 7(2), 35-55.

Common \& West, K. (2007). The corner. On be [CD]. New York, NY: G.O.O.D. Music.

Cooks, J. (2004). Writing for something: Essay, raps, and writing preferences. English Journal, 94(1), 72-76.

Darling-Hammond, L. (2004). The color line in American education: Race, resources, and student achievement. DuBois Review, 1, 213-246.

Dilworth, M. E. (Ed.). (1992). Diversity in teacher education. San Francisco, CA: Jossey-Bass.

Duncan-Andrade, J., \& Morrell, E. (2005). Turn up that radio, teacher: Popular cultural pedagogy in new century. Journal of School Leadership, 15, 284302.

Ellsworth, E. (1997). Teaching positions: Difference, pedagogy, and the power of address. New York NY: Teachers College Press.

Emdin, C. (2008). The three C's for urban science education. Phi Delta Kappan, $89(10), 772-775$.

Emdin, C. (2010). Urban science education for the hip-hop generation: Essential tools for the urban science educator and researcher. Boston, MA: Sense Publishers.

Fiasco, L. (2006). Hurt me soul. On Food \& Liquor [CD]. New York, NY: Atlantic Records. 
Fletcher, E., \& Glover, M. (1982). The message [Recorded by Grandmaster Flash and the Furious Five's]. On The Message [CD]. New York, NY: Sugar Hill Records.

Gay, G., \& Howard, T. (2000). Multicultural teacher education in the $21^{\text {st }}$ century. The Teacher Educator, 36(1), 1-16.

Hamilton, M. L. (2004). Professional knowledge, self-study and teacher education. In J. J. Loughran, M. L. Hamilton, V. K. LaBoskey, \& T. Russell (Eds.). International handbook of self-study of teaching and teacher education practices (pp. 375-419). Dordrecht, The Netherlands: Kluwer Academic Publishers.

Hamilton, M. L., Smith, L., \& Worthington, K. (2008). Fitting the methodology with the research: An exploration of narrative, self-study and auto-ethnography. Studying Teacher Education, 4(1), 17-28.

Harry, D., \& Stein, C. (1980). Rapture [Recorded by Blondie]. On Autoamerican [CD]. United Kingdom: Chrysalis Records.

Hill, M. L. (2009). Beats, rhymes, and classroom life: Hip-hop pedagogy and the politics of identity. New York, NY: Teachers College Press.

Irby, D., \& Hall, H. B. (2011). Fresh faces, new places: Moving beyond teacherresearcher perspectives in hip-hop based education. Urban Education, 46(22), 216-240.

Irby, D. (2006). "Do the Knowledge": A standards based hip-hop learning guide. Philadelphia, PA: Art Sanctuary.

Jeremiah, M. (1992). Rap lyrics: Instruments for language arts instruction. Western Journal of Black Studies, 16(2), 98-102.

Johnson, L. (2002). "My eyes have been opened": White teachers and racial awareness. Journal of Teacher Education, 53, 153-167.

King, J. (1991). Dysconscious racism: Ideology, identity, and the miseducation of teachers. Journal of Negro Education, 60(2), 133-146.

Kitwana, B. (2002). The Hip-hop generation: Young blacks and the crisis in African American culture. New York, NY: Basic Civitas Books.

LaBoskey, V. K. (2007). The methodology of self-study and its theoretical underpinnings. In J. J. Loughran, M. L. Hamilton, V. K. LaBoskey, \& T. L. Russell (Eds.), International handbook of self-study of teaching and teacher education practices (pp. 817-869). New York, NY: Springer.

Ladson-Billings, G. (1992). Libratory consequences of literacy: A case of culturally relevant pedagogical instruction for African-American students. The Journal of Negro Education, 61(3), 378-391.

Lensmire, T. J., \& Snaza, N. (2010). What teacher education can learn from blackface minstrelsy. Educational Researcher, 39(1), 413-421.

Loughran, J. (2006). A response to 'reflecting on the self.' Reflective Practice, 
$7(1), 43-53$.

Lowenstein, K. (2009). The work of multicultural teacher education: Reconceptualizing White teacher candidates as learners. Review of Educational Research, 79(1), 163-196.

Mason, J. (2002). Researching your own practice: The discipline of noticing. New York, NY: Routledge.

McLaren, P. (2007). Life in schools: An introduction to critical pedagogy in the foundations of education (5th ed.). Boston, MA: Pearson Allyn \& Bacon.

Milner, H. R., \& Smithey, M. (2003). How teacher educators created a course curriculum to challenge and enhance preservice teachers' thinking and experience with diversity. Teaching Education, 14, 293-305.

Milner, H. R. (2003). Teacher reflection and race in cultural contexts: History, meaning, and methods in teaching. Theory into Practice, 42, 173-180.

Milner, H. R. (2005). Stability and change in prospective teachers' beliefs and decisions about diversity and learning to teach. Teaching and Teacher Education, 21(7), 767-786.

Morrell, E., \& Duncan-Andrade, J. (2002). Promoting academic literacy with urban youth through engaging hip-hop culture. English Journal, 91(6), 8892.

Petchauer, E. (2009). Framing and reviewing hip-hop educational research. Review of Educational Research, 79, 946.

Pinnegar, S., \& Hamilton, M.L. (2009). Self study of practice as a genre of qualitative research: Theory, methodology, and practice. New York, NY: Springer.

Porfilio, B., \& Viola, M. (2012). Hip-Hop(e): The cultural practice and critical pedagogy of international hip-hop. New York, NY: Peter Lang.

Powell, C. (1991). Rap music: An education with a beat from the street. Journal of Negro Education, 60(3), 245-259.

Rice, J. (2003). The 1963 hip-hop machine: Hip-hop pedagogy as composition. College Composition and Communication, 54(3), 453-471.

Stovall, D. (2006). Can we relate: Hip-hop culture, critical pedagogy, and the secondary classroom. Urban Education, 41(6), 585-602.

Sullivan, R. (2003). Rap and race: It's got a nice beat, but what about the message? Journal of Black Studies, 33(5), 605-622. 